\title{
Large intestine obstruction complicated with perforation: A rare manifestation of Schistosoma mansoni infection
}

\author{
Department of Surgery, \\ Universidade Federal de São Paulo/Escola Paulista de Medicina - São Paulo, Brazil
}

\begin{abstract}
The authors report a case of a 25 year old Brazilian man with a history of crampy abdominal pain in the left iliac fossa for 2 weeks, abdominal distention, mucous diarrhea and anorexia. The patient presented signs of hemodynamic instability and a hard mass palpated in the left iliac fossa presented peritoneal irritation. At laparotomy, fecal peritonitis and a punched-out perforation of the midsigmoid colon were found. A left hemicolectomy was performed with terminal colostomy. Specimen examination revealed a thickened rectosigmoid wall, narrow lumen and multiple mucosal polyps. Microscopically, chronic granulomatous colitis with Schistosoma mansoni eggs confirmed the etiology. To the authors' knowledge, this is the first case of obstruction complicated with perforation due to mansoni schistosomiasis reported in the literature.
\end{abstract}

UNITERMS: Schistosomiasis. Colon obstruction. Large intestine.

\section{INTRODUCTION}

$O$ chistosomiasis remains an important public health problem worldwide. It is estimated that 200 million people are affected by its different forms, especially in underdeveloped countries in Asia, Africa, South America and some Caribbean islands. ${ }^{1}$

The main complication of mansoni schistosomiasis is portal hypertension and its consequences, particularly upper gastrointestinal hemorrhage, which constitutes the principal cause of death in these patients and occurs in its hepatosplenic form. ${ }^{2}$ The intestinal form is manifested more frequently by bowel irregularity of little relevance. ${ }^{3}$

Despite the high prevalence of the disease, surgical complications in the intestinal or hepatointestinal form are rare. The objective of this paper is to report on a case of sigmoid colon obstruction complicated with perforation caused by mansoni schistosomiasis.

\section{Address for correspondence:}

Fernando Antibas Atik

Av. Chibarás, 626 - ap.101

São Paulo/SP, Brasil - CEP 04076-003

\section{CASE REPORT}

A 25 year old Brazilian man was admitted into the emergency department of São Paulo Hospital, Federal University of São Paulo - Paulista School of Medicine, with a history of crampy abdominal pain, high in intensity, located in the left iliac fossa and beginning 2 weeks earlier. The pain was accompanied by abdominal distention with progressive and slow evolution, mucous diarrhea and anorexia. A few hours before admission, the pain suddenly got worse, becoming generalized, with the onset of nausea and bilious vomiting. He denied having had fever, weight loss and any episode of bowel irregularity previously. He came from an endemic area of mansoni schistosomiasis. The physical examination revealed a patient in bad condition: anemic, dehydrated, hypotensive (AP 80 x 40 $\mathrm{mmHg}$ ), tachycardic (HR $120 \mathrm{bpm}$ ), tachypneumic (30 bpm), with peripheral perfusion. The abdomen was distended, painful to palpation, especially in the left lower fossa where a mass could be felt. The latter was irregular, with imprecise limits, mobile, firm and with localized peritoneal irritation. Bowel sounds were reduced and the rectal examination found mucopurulent feces in the 
ampula, without masses. An abdominal roentgenogram showed dilated colon and small intestine, erasure of the left psoas muscle image, without pneumoperitoneum. The biochemical profile was unremarkable except for mild microcytic hypochromic anemia (hemoglobin of 10.1) and elevated creatinine (2.0). The leukocyte count (6600) was normal, but there was a shift to metamielocytes.

The patient's debility, associated with hemodynamic instability, refractory to fluid resuscitation and signs of peritoneal irritation, indicated surgical exploration. At laparotomy, 1.5 liters of stool was found in subphrenic spaces, cul de sacs and between bowel loops. A blockage of inflamed intestine and necrotic omentum was covering a punched out perforation (diameter $2 \mathrm{~cm}$ ) along the mesenteric border of the midsigmoid colon. A left hemicolectomy and omentectomy were performed and a terminal colostomy constructed with distal bowel closure (Hartman's operation).

The post-operative period was marked by subphrenic abscess formation managed medically and the patient was discharged on the seventh post-operative day without the need for any further therapeutic procedure.

Examination of the surgical specimen (Fig. 1) demonstrated its serosa covered by yellow-green plaques with an area of irregular perforation and hemorrhage. The colonic mucosa was edematous and multiple areas of hemorrhage were evident. The bowel wall at the rectosigmoid junction was markedly thickened $(2 \mathrm{~cm})$, leading to significant narrowing of its lumen. Multiple mucosal polyps were present in the ressected segment. Microscopic analysis of the ulcer margins revealed chronic colitis with innumerable granulomas containing viable Schistosoma mansoni eggs (Fig. 2), destruction of bowel wall architecture and fibrous peritonitis extending to the omentum. The patient was treated with oxamniquine $15 \mathrm{mg} / \mathrm{kg}$ in a single dose. Three months after surgery, he was still in good condition.

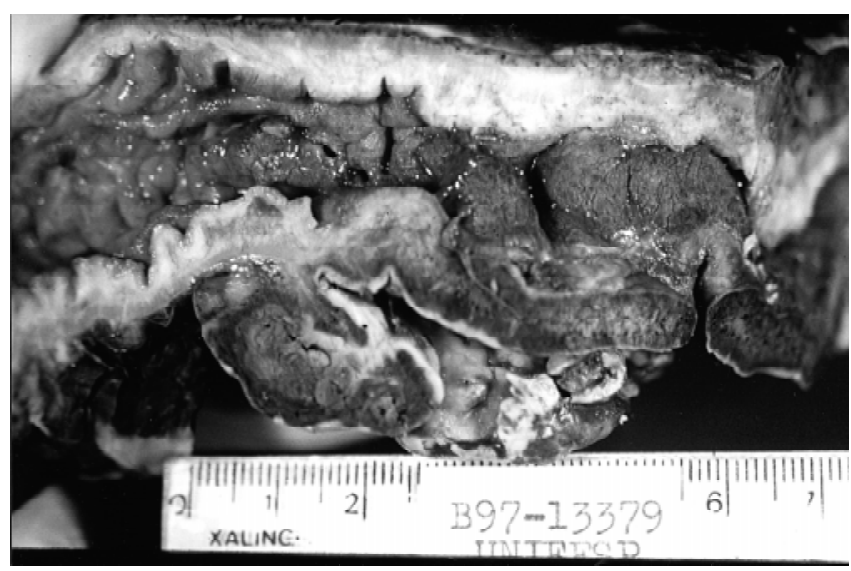

Figure 1 - Photograph of surgical specimen showing normal colon on the left. On the right, there is thickening of walls and loss of mucosa architecture with hemorrhage areas, followed by wall perforation.

\section{DISCUSSION}

Schistosomotic colitis is a very rare occurrence, seldom leading to significant alterations in colon anatomy, with remarkable clinical manifestations.

The incidence of schistosomotic colitis may be estimated by necropsy and radiology data. With this aim, Magalhães ${ }^{4}$ retrospectively reviewed 500 autopsies and 776 routine colon enemas. He found polyps in 21 autopsies, of which $38.8 \%$ were schistosomotic. Among the opaque enemas, $0.25 \%$ showed radiological evidence of disease.

Pontes ${ }^{5}$ described rectosigmoidoscopic findings in 576 patients with previously-diagnosed mansoni schistosomiasis. Forty-one percent of the examinations were normal. The most prevalent pathological alterations were hyperemia, edema, petechiae and granulation. Other less frequent findings were capillary congestion, varicosity, ulcers and polypoid lesions. These latter ones developed in submucosa, elevating the mucosa that becomes hyperplastic. Polyps may be pedunculated, but they are usually sessile. Ulcers develop later, when blood supply is jeopardized by polyp overgrowth.

The great majority of colitis caused by mansoni schistosomiasis is asymptomatic or oligosymptomatic, with the diagnosis being carried out by stool tests or rectal valve biopsy, with $80 \%$ to $90 \%$ accuracy. Surgical treatment has a limited role, with only a few cases described of intestinal obstruction, ${ }^{6-9}$ acute appendicitis, intestinal polyposis, ${ }^{10}$ pseudotumor ${ }^{3}$ and intestinal perforation. ${ }^{11,12}$ The cases reported as intestinal polyposis, pseudotumor and intestinal obstruction were usually misdiagnosed as colorectal neoplasias, especially in older patients.

Gelfand and Hammar ${ }^{6}$ postulated that these surgical complications may be determined by massive ovideposition, leading to significant immune response with development of granulomas and polyps. Wolfe ${ }^{13}$ believed these alterations occur only in epidemic areas, where parasitic density is high. Wright et al. ${ }^{7}$ reported a case of partial descending colon obstruction caused by schistosomotic granuloma. Medical treatment improved it after several months. They considered that the occurrence of this phenomenon might depend on the level of fibrosis and lumen narrowing.

Controversy remains, regarding the malignancy potential of schistosomotic colitis, because of its constant inflammatory nature leading to mucosa dysplastic alterations. ${ }^{14}$ However, Dimmette et al. ${ }^{15}$ did not observe neoplastic changes in schistosomotic colitis. 




Figure 2 - Optical micrograph showing intestinal villosities with severe inflammatory processes and Schistosoma mansoni eggs.

There are three case reports of intestinal obstruction caused by mansoni schistosomiasis, related to stenosing granulomatous processes and extensive pericolonic infiltration. Elmasalme et al. ${ }^{8}$ reported a case of sigmoid

\section{REFERENCES}

1. De Cock KM. Hepatosplenic schistosomiasis: a clinical review. Gut 1986;27:734-45.

2. Cheever AM, Andrade ZA. Pathological lesions associated with Schistosoma mansoni infection in man. Trans R Soc Trop Med Hyg 1967;61:629-39.

3. Elmasri SH, Boulos PB. Bilharzial granuloma of the gastrointestinal tract. Br J Surg 1976;63:887-90.

4. Magalhães A. Polyps of the large intestine. Schistosomotic polyps: a correlation of 500 autopsies and 776 roentgenographic studies. Rev Hosp Clin Fac Med S Paulo 1980;35:94-8.

5. Pontes J. Rectosigmoidoscopic aspects of mansoni schistosomiasis in Brazil. Dis Colon Rectum 1961;4:343-8.

6. Gelfand M, Hammar B. Acute intestinal obstruction from a granuloma due to Shistosoma haematobium in the large intestine. Trans R Soc Trop Med Hyg 1966;60:231-2.

7. Wright SG, Renton P, Swarbrick ET. Stricture of the descending colon due to schistosomiasis. Postgrad Med J 1976;52:602-4. obstruction caused by a huge schistosomotic granuloma that was confused with a neoplasm; the diagnosis was established only in the post-operative period. Two other cases of colon intussusception by big granulomas have also been published, one in the left colon ${ }^{3}$ and the other in the ileocecal. ${ }^{9}$ Regarding infection by Schistosoma haematobium, there are two other reports on colon intussusception, by Gelfand and Hamman. ${ }^{6}$

In the present case, we found sigmoid colon obstruction complicated with perforation, initially blocked by a large omentum, forming a pericolonic abscess. The colon showed incontestable signs of chronic schistosomotic colitis, with multiple polyps and ulceration. No other report of intestinal obstruction complicated with perforation was found in the literature consulted.

We conclude that because of the high prevalence of schistosomiasis worldwide, we should always consider it in differential diagnosis of intestinal obstruction, especially in countries where it is endemic.

8. Elmasalme FN, Raheem MA, Badawy A, Zuberi SR, Matbouli SA. Rectosigmoid bilharzioma causing intestinal obstruction. J Pediatr Surg 1997;32:631-3.

9. Iyer HV, Abaci IF, Rehnke EC, Enquist IF. Intestinal obstruction due to schistosomiasis. Am J Surg 1985;149:409-11.

10. Hariton I, Celli BB. Schistosomiasis mansoni as a cause of granuloma of the large intestine - report of three cases. Dis Colon Rectum 1966;9:279-82.

11. Culliford A, Ibrahim I, Worth MH. Traumatic perforation of the sigmoid colon through schistosomal ulcerations. Am J Surg 1975;129:705-8.

12. Gambescia RA, Kaufman B, Noy J, Young J, Tedesco FJ. Schistosoma mansoni infection of the colon: a case report and review of the late colonic manifestations. Dig Dis 1976;21:988-91.

13. Wolfe HRI. The surgical treatment of tropical diseases of the colon and rectum. Proc R Soc Med 1967;60:50-4.

14. Ming-Chai $\mathrm{C}$, et al. Colorectal cancer and schistosomiasis. Lancet 1981;2:971-3.

15. Dimmette RM, Elwi AM, Sproate HF. Relationship of schistosomiasis to polyposis \& adenocarcinoma of large intestine. Am J Clin Pathol 1956;26:266-9.

\section{Resumo}

Os autores relatam o caso de um paciente masculino, de 25 anos, admitido com história de dor em cólica na fossa ilíaca esquerda há duas semanas, distensão abdominal, diarréia mucóide e anorexia. Evoluiu com instabilidade hemodinâmica, uma massa endurecida era palpada na fossa ilíaca esquerda com sinais de irritação peritoneal. Na laparotomia, foram encontrados peritonite fecal e uma perfuração do cólon sigmóide. Realizada hemicolectomia esquerda com colostomia terminal. O exame anátomo-patológico revelou espessamento da parede do cólon com estreitamento de sua luz e múltiplos pólipos na mucosa. O exame histopatológico confirmou a causa da obstrução como colite granulomatosa crônica com ovos viáveis de Schistosoma mansoni. Este é o primeiro caso de obstrução colônica complicada com perfuração causada por esquistossomose mansônica relatado na literatura consultada. 